\title{
Flat face-microstomia-ear anomaly syndrome
}

INSERM

\section{Source}

INSERM. (1999). Orphanet: an online rare disease and orphan drug data base. Flat facemicrostomia-ear anomaly syndrome. ORPHA:1968

Flat face-microstomia-ear anomaly syndrome is a rare, genetic, multiple congenital anomalies/dysmorphic syndrome characterized by dysmorphic facial features, including high forehead, elongated and flattened midface, arched and sparse eyebrows, short palpebral fissures, telecanthus, long nose with hypoplastic nostrils, long philtrum, high and narrow palate and microstomia with downturned corners. Ears are characteristically malformed, large, low-set and posteriorly rotated and nasal speech is associated. There have been no further descriptions in the literature since 1994. 